\title{
Nephropathy and Neuropathy in Diabetic Patients with Chronic Hepatitis C Virus Infection
}

\author{
Mohamed Y. Abdel Aziz ${ }^{1 *}$, Mahmoumd M El-Bendary², Mohamed M El-Arman ${ }^{3}$ \\ (1) Internal Medicine, (2) Tropical Medicine, and (3) Clinical Pathology Deptartments, Faculty of Medicine; Mansoura University, Egypt
}

\begin{abstract}
Introduction: Several reports described an association between type 2 diabetes mellitus (DM) and chronic hepatitis $\mathrm{C}$ virus $(\mathrm{HCV})$ infection. Chronic $\mathrm{HCV}$ infection is prevalent in Egypt. The present work aimed to evaluate the prevalence of proteinuria and neuropathy among diabetic patients with and without chronic HCV infection
\end{abstract}

Methods: A total of 70 diabetic patients were recruited from patients that attended the outpatient clinic of Mansoura Specialized Medical University Hospital. They were evaluated for diabetic retinopathy, peripheral neuropathy, autonomic neuropathy, high blood pressure, urinary albumin excretion (UAE), serum creatinine, lipid profile and assay of HCV-RNA.

Results: The prevalence of HCV infection among this group of diabetic patients was $35.7 \%$ compared to $10 \%$ in a matched control group $(\mathrm{P}<0.05)$. Diabetic patients with chronic HCV infection $(n=45)$ and diabetic patients without $\mathrm{HCV}$ infection $(\mathrm{n}=25)$ had no significant differences in diabetes type, diabetes duration, prevalence of hypertension, level of glycosylated hemoglobin or prevalence of diabetic retinopathy. The prevalence of macroalbuminuria, peripheral neuropathy and autonomic neuropahty was higher among diabetic patients with chronic HCV infection $(\mathrm{P}<0.05)$. Also, diabetic patients with chronic $\mathrm{HCV}$ infection had higher mean arterial pressure, higher serum creatinine, higher triglyceride and cholesterol levels, and higher UAE $(\mathrm{P}<0.05)$.

Conclusion: A high prevalence of $\mathrm{HCV}$ infection is observed among this group of Egyptian diabetic patients, and it was associated with higher rates of nephropathy and peripheral neuropathy compared to diabetic patients without $\mathrm{HCV}$ infection.

\footnotetext{
* Corresponding author; associate professor in Faculty of Medicine, Mansoura University, El-Mansoura, Egypt.

E mail: nadayakout@yahoo.com
}

Key words: Diabetes mellitus; Egypt; HCV infection; Nephropathy; Neuropahty; Retinopathy

\section{The authors declared no conflict of interest}

\section{Introduction}

The prevalence of diabetes mellitus (DM) and its complications is increasing worldwide. Vascular complications of DM are a common cause of mortality and morbidity in diabetics and constitute the major clinical burden of the disease. Type 1 and type 2 diabetes have distinct etiologies, but patients with either disease are at risk of developing the same range of microvascular and macrovascular complications including nephropathy, neuropathy, retinopathy and atherosclerosis.

Throughout the world, the number of patients requiring hemodialysis for diabetic nephropathy has increased enormously [1]. Although several factors, such as poor glycemic control, high blood pressure, proteinuria, lipid abnormalities, and genetic predisposition were identified as contributing to the progression of diabetic nephropathy, it is highly suspected that there may be other unidentified factors.

Hepatitis C virus (HCV) is both a cause and a complication of chronic renal disease. Chronic infection with $\mathrm{HCV}$ can lead to the immune complex syndromes of cryoglobulinemia and membranoproliferative glomerulonephritis (MPGN). Lymphoproliferative disorders, Sjogren syndrome, porphyria cutanea tarda, and neuropathies are other extrahepatic manifestations of $\mathrm{HCV}$ infection. The pathophysiologic basis for most of these syndromes seems immunologic [2].

Several reports described an association between type 2 diabetes and chronic HCV infection. Type 2 diabetes was reported to be commoner in patients with chronic $\mathrm{HCV}$ infection [3-6], indicating that HCV may promote the development of type 2 diabetes in susceptible individuals. Hepatic steatosis and cirrhosis, both features 
Table 1: Clinical and biochemical characteristics of the study patients

\begin{tabular}{ll}
\hline Clinical and biochemical characteristics & Value \\
\hline DM type 1, number (\%) & $17(24.3 \%)$ \\
DM type 2, number (\%) & $53(75.7 \%)$ \\
Peripheral neuropathy, number (\%) & $40(57.2 \%)$ \\
Autonomic neuropahty, number (\%) & $11(15.7 \%)$ \\
Nephropathy, number (\%) & $29(41.4 \%)$ \\
Retinopathy, number (\%) & $20(28.6 \%)$ \\
Hypertension, number (\%) & $22(31.4 \%)$ \\
MAP mmHg, mean $\pm \mathrm{SD}$ & $100 \pm 15$ \\
Serum creatinine (mg/dl), mean $\pm \mathrm{SD}$ & $0.95 \pm 0.1$ \\
Serum triglycerides (mg/dl), mean $\pm \mathrm{SD}$ & $119 \pm 36$ \\
Serum cholesterol (mg/dl), mean $\pm \mathrm{SD}$ & $195 \pm 35$ \\
HbA1c (\%), mean $\pm \mathrm{SD}$ & $8.2 \pm 2.5$ \\
Creatinine clearance (ml/min), mean $\pm \mathrm{SD}$ & $126 \pm 31$ \\
UAE (mcg/ml), mean $\pm \mathrm{SD}$ & $64 \pm 59$ \\
\hline
\end{tabular}

MAP: mean arterial pressure; HA1c: glycosylated hemoglobin; UAE: urinary albumin excretion.

of chronic HCV infection, have been associated with abnormal glucose regulation and insulin resistance [7]. Interestingly, a high prevalence of $\mathrm{HCV}$ infection was reported in diabetic patients [8].

Chronic HCV infection is prevalent in Egypt. In a study of 55,922 potentially healthy asymptomatic blood donors screened between 2000 and 2007, the cumulative seroprevalence of $\mathrm{HCV}$ infection was $12 \%$ [9].

The present work aimed to study the prevalence of HCV infection among a group of Egyptian diabetic patients, and to evaluate the prevalence of proteinuria and neuropathy among diabetic patients with and without chronic HCV infection.

\section{Methods}

A total of 70 diabetic patients were recruited from patients that attended the outpatient clinic of diabetes and endocrine unit, Mansoura Specialized Medical University Hospital, in the summer months of 2005. This included 15 patients with type 1 diabetes and 55 patients with type 2 diabetes mellitus. Thirty normal healthy volunteers, of matched age and sex were taken as a control group. None of the studied cases had a history of previous cardiac, pulmonary, renal or endocrine disorders other than diabetes mellitus.
Diabetic patients were evaluated for evidence of diabetic retinopathy, peripheral neuropathy, autonomic neuropathy, high blood pressure (BP) and cardiovascular status. Investigations included urinary albumin excretion (UAE), serum creatinine, lipid profile and assay of HCV-RNA. Urinary albumin concentration was measured by radioimmunoassay. Urine samples were stored at $-20^{\circ} \mathrm{C}$ and thawed once before measurement. The inter- and intra-assay coefficients of variation for UAE were 11 and 4\% respectively. Assay of HCV-RNA by polymerase chain reaction (PCR) was carried out on frozen samples using ultraspec kit (Biotecx Laboratories Inc. 6023 South Loop East, Houston, Texas 77033. USA). Peripheral neuropathy was diagnosed based on neuropathic symptoms and impaired vibration sense. Autonomic neuropathy was diagnosed by the presence of postural hypotension. Nephropathy was diagnosed by the presence of persistent albuminuria of 20 to $200 \mathrm{mg} / 24$ hours (microalbuminuria) in at least three occasions in the absence of urinary tract infection. Macroalbuminuria was diagnosed when persistent albuminuria $\geq 300 \mathrm{mg} / 24$ hours was found. Chi square test was used to compare proportions. Student-t test was used to compare means. P value $<0.05$ was considered statistically significant.

\section{Results}

The study group included 20 males and 50 females, with a mean age of $47 \pm 18$ years. The control group consisted of nine males and 21 females with a mean age of $45 \pm 13$ years. None of the patients tested positive for $\mathrm{HBV}$ infection. The prevalence of $\mathrm{HCV}$ infection among diabetic patients was $35.7 \%$ compared to $10 \%$ in the control group $(\mathrm{P}<0.05)$. The clinical characteristics of the diabetic patients are described (Table 1).

Diabetic patients with chronic HCV infection $(n=45)$ and diabetic patients without HCV infection $(n=25)$ had no significant differences in diabetes type, diabetes duration, prevalence of hypertension, or level of glycosylated hemoglobin. Diabetic retinopathy was not significantly different between the two groups (Table 2).

The prevalence of macroalbuminuria, peripheral neuropathy and autonomic neuropahty was higher among diabetic patients with chronic HCV infection. Also, diabetic patients with chronic HCV infection had higher mean arterial pressure, higher serum creatinine, higher triglyceride and cholesterol levels, and higher UAE (Table 2).

Nephropathic patients with and without HCV infection were not different regarding diabetic duration, mean arterial pressure or HbA1c level. However, nephropathic patients with $\mathrm{HCV}$ infection were less likely to have diabetic retinopathy (Table 3 ). 
Table 2: Comparison of diabetic patients with and without HCV infection

\begin{tabular}{lll}
\hline Clinical and biochemical characteristics & HCV negative group (n=45) & HCV positive group (n=25) \\
\hline Diabetic duration (months), mean \pm SD & $94 \pm 55$ & $101 \pm 78$ \\
DM type 1, number (\%) & $12(27)$ & $5(20)$ \\
DM type 2, number (\%) & $33(73)$ & $20(80)$ \\
Hypertension, number (\%) & $13(28.9)$ & $9(36)$ \\
MAP (mmHg), mean \pm SD & $93 \pm 15$ & $104 \pm 6^{*}$ \\
Nephropathy, number (\%) & $15(33.3)$ & $14(56)^{*}$ \\
Microalbuminuria, number (\%) & $10(22.2)$ & $8(32)$ \\
Macroalbuminuria, number (\%) & $5(11.1)$ & $6(24)^{*}$ \\
Diabetic retinopathy, number (\%) & $11(24.4)$ & $9(36)$ \\
Background diabetic retinopathy (\%) & $6(13.3)$ & $4(16)$ \\
Proliferative diabetic retinopathy (\%) & $5(11.1)$ & $5(20)^{*}$ \\
Peripheral neuropathy, number $(\%)$ & $21(46.7)$ & $19(76)^{*}$ \\
Autonomic neuropathy, number (\%) & $5(11.1)$ & $6(24)^{*}$ \\
Serum creatinine (mg/dl), mean $\pm \mathrm{SD}$ & $0.81 \pm 0.11$ & $0.97 \pm 0.12^{*}$ \\
Serum triglycerides (mg/dl), mean $\pm \mathrm{SD}$ & $109 \pm 33$ & $123 \pm 36^{*}$ \\
Serum cholesterol (mg/dl), mean $\pm \mathrm{SD}$ & $166 \pm 32$ & $195 \pm 36^{*}$ \\
HbA1c (\%), mean $\pm \mathrm{SD}$ & $7.9 \pm 2.2$ & $8.3 \pm 2.3$ \\
Creatinine clearance (ml/min), mean $\pm \mathrm{SD}$ & $111 \pm 21$ & $121 \pm 23$ \\
UAE (mcg/ml), mean $\pm \mathrm{SD}$ & $43 \pm 35$ & $111 \pm 79^{*}$ \\
\hline
\end{tabular}

MAP: mean arterial pressure; HbA1c: glycosylated hemoglobin; UAE: urinary albumin excretion $* \mathrm{P}<0.05$

\section{Discussion}

Both HCV infection and diabetes are common health problems in Egypt. HCV infection is known to have a wide variety of manifestations in the kidney. The direct effects of HCV infection on the kidney include membranous nephropathy, cryoglobulinemia, and membranoproliferative glomerulonephritis (MPGN). The presence of HCV worsens the progression of several renal diseases, and it is more prevalent in patients with type 2 diabetic nephropathy [8]. Therefore, it is possible that $\mathrm{HCV}$ contributes to the progression of renal disease in diabetic patients $[10,11]$.

In the present study, prevalence rate of $\mathrm{HCV}$ infection among a group of Egyptian diabetics was found to be $35.7 \%$ and it was significantly higher than healthy volunteers $(10 \%)$. Kaabia et al performed a crosssectional study to determine the HCV seroprevalence in 1269 diabetic and 1315 non-diabetic patients in Tunisia; in the diabetic group, $1.3 \%$ were found to be HCVinfected compared with $0.6 \%$ in the control group $(\mathrm{P}=$ $0.06)$ [12].
Mehta et al examined the prevalence of type 2 diabetes among persons with HCV infection in a representative sample of the general adult population of the United States. They concluded that persons 40 years of age or older with $\mathrm{HCV}$ infection were more than three times more likely than those without $\mathrm{HCV}$ infection to have type 2 diabetes after adjustment for age, ethnicity, body mass index, socioeconomic status and illicit drug use [13]. The reason for this association between HCV infection and diabetes is not clear. It has been postulated that HCV could infect pancreatic islet cells and thereby directly induce damage to cells [3].

Despite lack of difference in diabetes type, diabetes duration, prevalence of hypertension, or level of glycosylated hemoglobin, diabetic patients with chronic $\mathrm{HCV}$ infection in this study were more likely to have macroalbuminuria than diabetic patients without $\mathrm{HCV}$ infection. In addition, diabetic patients with chronic HCV infection had higher mean arterial pressure, higher serum creatinine, and higher UAE. Arao and their co-workers did not find a significant difference in progression to ESRD between HCV and non-HCV diabetic patients [6]. 
Table 3: Comparative analysis of other risk factors for diabetic nephropathy between nephropathic patients with and without HCV infection

\begin{tabular}{lll}
\hline Patient characteristics & $\begin{array}{l}\text { Nephropathy } \\
\text { in the presence of HCV infection } \\
(\mathbf{n}=\mathbf{1 7})\end{array}$ & $\begin{array}{l}\text { Nephropathy } \\
\text { in the absence of HCV infection } \\
(\mathbf{n}=\mathbf{1 2})\end{array}$ \\
\hline Diabetic duration (months), mean \pm SD & $100 \pm 82$ & $101 \pm 77$ \\
MAP (mmHg), mean \pm SD & $107 \pm 12$ & $103 \pm 10$ \\
Retinopathy, number (\%) & $6(35.3 \%)$ & $6(50 \%)^{*}$ \\
HbA1c (\%), mean \pm SD & $8.6 \pm 3.4$ & $8.2 \pm 2.9$ \\
\hline
\end{tabular}

MAP: mean arterial pressure; HA1c: glycosylated hemoglobin

$* \mathrm{P}<0.05$

However, the rate of progression of renal disease was reported to be worse in the HCV group [11]. Soma et al investigated the prevalence of HCV infection in 2370 patients who had a renal biopsy over a four-year period. The highest prevalence of HCV infection was found in type II diabetes-related glomerulosclerosis (24 of 123; $19.5 \%$ ). After renal biopsy, the decline of renal function was significantly greater in the HCV-positive group than in the $\mathrm{HCV}$-negative group $(\mathrm{P}=0.001)$. In addition, they randomly examined $\mathrm{HCV}$ infection in 545 outpatients and inpatients with type II diabetes mellitus that did not undergo renal biopsy. Of these, 56 patients were positive for HCV antibody (10.3\%), and their proteinuria was heavier than in $489 \mathrm{HCV}$-negative patients $(\mathrm{P}=0.001)$ [14].

Poorer renal survival in $\mathrm{HCV}$ positive patients may be due to direct effects of HCV in the kidney [11]. GarcoaValdecases and his co-workers reported that HCV infection is associated with membranoproliferative glomerulonephritis and nephrotic syndrome [15]. Okada et al found immune complex deposition, cryoglobulinlike structure, and $\mathrm{HCV}$ core protein in the glomeruli of those affected patients [16]. Immune complex glomerulonephritis has been reported to occur at a higher frequency in patients with diabetic nephropathy than in the non-diabetic population [15]. Associated immune mediated glomerulonephritis in patients with diabetic nephropathy usually displays a rapid progression to renal failure [17]. There is also the possibility that HCV may infect renal tissue, such as mesangial cells, and directly contribute to renal damage [18]. In addition, it is well known that $\mathrm{HCV}$ infection frequently causes cirrhosis. In cirrhosis, an intense intrarenal vasoconstriction and hypoperfusion may contribute to the rapid deterioration of renal function [15].

In the present work, six out of 14 diabetic HCV-positive patients with nephropathy had diabetic retinopathy.
Diabetic retinopathy is known to be present in virtually all type 1 diabetics with nephropathy, and absence of retinopathy should lead to more than usual consideration of other non-diabetic causes of renal disease [19]. On the other hand, up to one third of cases with diabetic retinopathy, even of the proliferative type, may occur in absence of renal disease or proteinuria [20].

In the absence of renal biopsy, we can only suggest the possibility of $\mathrm{HCV}$ infection being directly responsible for some cases of nephropathy in the present study. There are reports of renal biopsies in diabetic patients whose history was inconsistent with diabetic nephropathy (hematuria, heavy proteinuria in absence of retinopathy, or short history of diabetes) [21], and it was found that diabetic patients with HCV infection were less likely to have diabetic nephropathy as the primary renal diagnosis.

\section{Conclusion}

A high prevalence of HCV infection was observed among this group of Egyptian diabetic patients. This may have an adverse effect on the progression of nephropathy. Close monitoring is warranted for diabetics with $\mathrm{HCV}$ infection, with special consideration to renal and retinal complications.

\section{References}

1. D'Amico G. Comparability of different registries on renal replacement therapy. Am J Kidney Dis. 1995 Jan;25(1):113-8.

2. Ali A, Zein NN. Hepatitis C infection: a systemic disease with extrahepatic manifestations. Cleve Clin J Med. 2005 Nov;72(11):1005-8, 1010-4, 1016.

3. Mehta SH, Strathdee SA, Thomas DL. Association between hepatitis $\mathrm{C}$ virus infection and diabetes mellitus. Epidemiol Rev. 2001;23(2):302-12. 
4. Wilson C. Hepatitis C infection and type 2 diabetes in American-Indian women. Diabetes Care. 2004;27(9):2116-9.

5. Antonelli A, Ferri C, Fallahi P, Pampana A, Ferrari SM, Goglia F, Ferrannini E. Hepatitis C virus infection: evidence for an association with type 2 diabetes. Diabetes Care. 2005 Oct;28(10):2548-50.

6. Arao M, Murase K, Kusakabe A, Yoshioka K, Fukuzawa Y, Ishikawa T, Tagaya T, Yamanouchi K, Ichimiya H, Sameshima Y, Kakumu S. Prevalence of diabetes mellitus in Japanese patients infected chronically with hepatitis C virus. J Gastroenterol. 2003;38(4):355-60.

7. Shintani Y, Fujie H, Miyoshi H, Tsutsumi T, Tsukamoto K, Kimura S, Moriya K, Koike K. Hepatitis C virus infection and diabetes: direct involvement of the virus in the development of insulin resistance. Gastroenterology. 2004 Mar;126:840-8.

8. Simó R, Hernández C, Genescà J, Jardí R, Mesa J. High prevalence of hepatitis $\mathrm{C}$ virus infection in diabetic patients. Diabetes Care. 1996 Sep;19(9):998-1000.

9. Ismail AM, Ziada HN, Sheashaa HA, Shehab El-Din AB. Decline of viral hepatitis prevalence among asymptomatic Egyptian blood donors: a glimmer of hope. Eur J Intern Med. 2009 Sep;20(5):490-3.

10. Meyers CM, Seeff LB, Stehman-Breen CO, Hoofnagle JH. Hepatitis $\mathrm{C}$ and renal disease: an update. Am J Kidney Dis. 2003 Oct;42(4):631-57.

11. Crook ED, Penumalee S, Gavini B, Filippova K. Hepatitis $\mathrm{C}$ is a predictor of poorer renal survival in diabetic patients. Diabetes Care. 2005 Sep;28(9):2187-91.

12. Kaabia N, Ben Jazia E, Slim I, Fodha I, Hachfi W, Gaha R, Khalifa M, Hadj Kilani A, Trabelsi H, Abdelaziz A, Bahri F, Letaief A. Association of hepatitis $\mathrm{C}$ virus infection and diabetes in central Tunisia. World $\mathrm{J}$ Gastroenterol. 2009 Jun;15(22):2778-81.

13. Mehta SH, Brancati FL, Sulkowski MS, Strathdee SA, Szklo M, Thomas DL. Prevalence of type 2 diabetes mellitus among persons with hepatitis $\mathrm{C}$ virus infection in the United States. Ann Intern Med. 2000 Oct;133(8):592-9.

14. Soma J, Saito T, Taguma Y, Chiba S, Sato H, Sugimura $\mathrm{K}$, Ogawa S, Ito S. High prevalence and adverse effect of hepatitis $\mathrm{C}$ virus infection in type II diabetic-related nephropathy. J Am Soc Nephrol. 2000 Apr;11(4):690-9.

15. Garcia-Valdecasas J, Bernal C, Garcia F, Cerezo S, Umana WO, von Albertini B, Kimmel PL. Epidemiology of hepatitis $\mathrm{C}$ virus infection in-patients with renal disease. J Am Soc Nephrol. 1994 Aug;5(2):186-92.

16. Okada K, Takishita Y, Shimomura H, Tsuji T, Miyamura T, Kuhara T, Yasutomo K, Kagami S, Kuroda Y. Detection of HCV core protein in glomeruli of patients with membranous glomerulonephritis. Clin Nephrol. 1996 Feb;45(92):71-6.

17. Sène D, Limal N, Cacoub P. Hepatitis C virusassociated extrahepatic manifestations: a review. Metab Brain Dis. 2004 Dec;19(3-4):357-81.

18. Abbott KC, Lentine KL, Bucci JR, Agodoa LY, Koff JM, Holtzmuller KC, Schnitzler MA. Impact of diabetes and hepatitis after kidney transplantation on patients who are affected by hepatitis C virus. J Am Soc Nephrol. 2004 Dec;15(12):3166-74.

19. Parving HH, Hommel E, Mathiesen E, Skøtt P, Edsberg B, Bahnsen M, Lauritzen M, Hougaard P, Lauritzen E. Prevalence of microalbuminuria, arterial hypertension, retinopathy and neuropathy in patients with insulin dependent diabetes. Br Med J (Clin Res Ed). 1988 Jan;296(6616):156-60.

20. West KM, Erderich LJ, Strober JA. A detailed study of risk factors for retinopathy and nephropathy in diabetes. Diabetes. 1980 Jul;29(7):501-8.

21. O'Neill WM Jr, Wallin JD, Walker PD. Hematuria and red blood cell casts in typical diabetic nephropathy. Am J Med. 1983 Mar;74(3): 389-95. 